\title{
Effect of Health Instructions on Anxiety Levels and Claustrophobia Among Female Adolescents Undergoing Magnetic Resonance Imaging
}

Entsar Kamel Mohammed: Lecturer of Medical Surgical Nursing, Faculty of Nursing, Menoufia University,

Josephin Atef Lawend: Lecturer of Pediatric Nursing,

Faculty of Nursing, Mansoura University,

Howida Abu Ellife: Assistant professor of Maternal and Newborn Health Nursing, Faculty of Nursing, Menoufia University

\section{Abstract}

Over 80 million MRI procedures are now performed each year worldwide. Magnetic resonance imaging (MRI) is a frequently used imaging technique not only for diagnostic purposes but also in research settings. Adolescent girls report a greater number of worries, more separation anxiety, and higher levels of generalized anxiety. Claustrophobia is common during MR scanning because of the enclosed nature of cylindrical whole-body MR scanners. This study aimed to investigate the effect of health instructions on anxiety levels and claustrophobia among female adolescents undergoing Magnetic Resonance Imaging. A quasi- experimental research design was used. This study was conducted at waiting area of El Menofia University Hospital. Four tools were used to collect data; Socio-Demographic characteristic of Female Adolescents structure questioner sheet to assess knowledge related to claustrophobia Assessment sheet, and State-Trait Anxiety Inventory sheet. The majority of female adolescent had unsatisfactory knowledge in pretest regarding preparation before MRI exam as compared to post test. There was highly statistically significant difference among levels of anxiety from pre test and post test. Conclusion; Female adolescent who are undergoing magnetic resonance imaging examination cannot terminate the procedure due to producing anxiety and claustrophobia, so health instructions for those is very necessary, which has an effect on reducing anxiety level and claustrophobia related to magnetic resonance imaging examination. Recommendations; The researchers suggested conduction of a designed program for patients who cannot terminate the procedure successfully and reappointed for another examination, Patient meeting with psychologist before MRI, Establishing enjoyable posters and pamphlets into the MRI waiting room, Teach the female adolescents' methods of coping therapeutically with claustrophobia and anxiety, Presences of relative with female adolescents during preparation for MRI

Key words: Health Instructions, anxiety levels , Claustrophobia, Magnetic Resonance Imaging 


\section{Introduction}

Magnetic resonance Imaging (MRI) has been described as the most important medical innovation in the last 25 years. There has been an enormous increase in the use of this modality in the clinical setting. Over 80 million MRI procedures are now performed each year worldwide. Magnetic resonance imaging (MRI) is a frequently used imaging technique not only for diagnostic purposes but also in research settings ${ }^{(\mathbf{1 - 3}) .}$

Magnetic resonance imaging (MRI) is known as a physiologically noninvasive technique. Individuals being scanned, sometimes experience substantial anxiety as a result of the scanning procedures or environment. During clinical scans25$37 \%$ of patients experience anxiety of moderate intensity. It has been reported that $13 \%$ of female adolescent patients undergoing MRI experience panic attacks during the procedure. The duration of an imaging sequence is about one to nine minutes and the duration of a total examination of one patient is between 20 and 90 minutes ${ }^{(4,5)}$

Physicians use the MR examination to help diagnose or monitor treatment for conditions such as: tumors of the chest, abdomen or pelvis, certain types of heart problems, diseases of the liver, other abdominal organs, diseases of the small intestine, cysts, solid tumors in the kidneys and other parts of the urinary tract, tumors and other abnormalities of the reproductive organs (e.g., uterus, ovaries), endometriosis, suspected uterine congenital abnormalities in women undergoing evaluation for infertility, and breast cancer. ${ }^{(6)}$

Magnetic field the scanner is built so that the patients lie inside the scanner in a tunnel, approximately 2 meters long and 60 centimeters wide, with the examined organ in the centre of the tunnel. This means that the head and body will be inside the tunnel for most examinations. The average scanner is about 2 meters wide, 2 meters high and 2.5 meters long, although newer scanners may be somewhat smaller. MRI is a technique that is sensitive to motion during image data collection which may impair image quality and create so-called motion artefacts. ${ }^{(\mathbf{7 , 8 , 9})}$ Meanwhile, individual risks should be evaluated before the MRI examination such as; Aneurysm clip(s), Any metallic fragment or foreign body, Aortic stent graft, Prosthetic heart valves and annuloplasty rings, Haemodynamic monitoring and temporary pacing devices, eg, Swan-Ganz catheter, Haemodynamic support devices, Cardiac pacemaker, 
Implanted cardioverter-defibrillator (ICD), defibrillator leads, Electronic implant or device, eg, insulin pump or other infusion pump, ear implants, Neurostimulation system, Shunt (spinal or intraventricular), Vascular access port and/or catheter, Joint replacement (eg, hip, knee, etc), Any type of prosthesis (eg, eye, etc), Tattoo or permanent makeup, Body piercing jewelers, Hearing aid, Renal insufficiency, Known/possible pregnancy or breast feeding. (10)

Anxiety is one of the most common psychological disorders in school-aged children and adolescents worldwide. Adolescent girls report a greater number of worries, more separation anxiety, and higher levels of generalized anxiety $(\mathbf{1 1 , 1 2 , 1 3 , 1 4 )}$. Anxiety in general is regarded as a common problem by radiographers. It is a multifaceted phenomenon that in the specific case of patients undergoing an MRI procedure, often involves fear of enclosed places (claustrophobia), pain, and worries about what the test might reveal. Most people have experienced anxiety at one point in life. We can distinguish two different forms of anxiety, state anxiety and trait anxiety. Trait anxiety refers to the general tendency of a person to be anxious, whereas state anxiety refers to anxiety experienced at one moment in time. ${ }^{(15,16)}$

Reducing anxiety especially for anxious female patients during MRI procedures is important for three reasons. First, it will help female patients to have a better experience with the procedure, which will in turn help them to be less anxious on potential follow-up scans. Second, the time needed to make a scan can potentially be decreased. Furthermore, when female patients are calm they tend to move less, which may decrease the amount of rescans needed because of bad image quality due to movement. ${ }^{(17)}$

Claustrophobia may be defined as anxiety in situations with confined freedom of movement. Claustrophobia is common during MR scanning because of the enclosed nature of cylindrical whole-body MR scanners. When a patient undergoes an unsuccessful MR examination, the clinical team must decide if the information can be gained from another procedure; however, in many cases, it is necessary to repeat the MR scan using sedation or general anaesthesia (GA). Frequently, it is judged that sedation will not be sufficient and the claustrophobic patient will request to be "asleep" for the procedure. ${ }^{(18,19)}$ 
For coping strategies, not all patients can cope with the situation and interrupt the examination prematurely due to panic attacks or claustrophobia, One will try to adapt the outcomes, by either changing the external situation (e.g. run away) or the internal situation (e.g. try to control the anxiety). Then the new situation will be reinterpret and the cycle continues. ${ }^{(20)}$

Some studies have shown that the number of children who needed sedation or anesthesia could be diminished with the adjusted preparation and/or realization of the examination. ${ }^{(21,22)}{ }^{(23)}$ who Suggests that increased information about the MRI scanning procedure and expected experiences during the scan may help female adolescents' to lie still during the sequences, with a decrease in motion artifacts. Furthermore, individual differences in levels of state anxiety can interact with task effects in healthy volunteers; for example, higher state anxiety was correlated with stronger insular responses to presentation of negative emotional material.

Nurse play an important role in prepares female adolescents' for scanning procedure before, during, and after the scanning. As MRI is becoming increasingly applicable and common for adults as well as for children it is important to study patients' experiences and the adjusted preparation and realization of MRI examinations. If the adjusted preparation and realization of examinations facilitates for patients undergoing an MRI then there will be a gain both for patient comfort and for efficiency in the use of resources. ${ }^{(24)}$

\section{Significance of the study:}

Clinical experience with the new technology of magnetic resonance imaging (MRI) has indicated that the procedure may produce anxiety in a number of adolescent patients, to the extent that occasionally a patient may be unwilling to undergo the procedure and adolescent child patients who are undergoing magnetic resonance imaging examination cannot terminate the procedure successfully due to producing anxiety and claustrophobia. So, this research is conducted to investigate the effectiveness of health instructions on reducing anxiety levels and claustrophobia among female adolescents' undergoing Magnetic Resonance Imaging.

Aim of the study: To investigate the effect of health instructions on anxiety levels and claustrophobia among female adolescents undergoing Magnetic Resonance Imaging.

\section{Research Hypotheses:}

Female adolescent undergoing resonance imaging who receiving health instruction 
was reducing anxiety level and claustrophobia after program implementation

\section{Materials and Method:}

\section{Research Design:}

A quasi- experimental research design was used in this study.

The present study was carried out through:

\section{Technical Design:}

The technical design includes; the setting, sample, and tools used in the study.

\section{Setting:}

The study was conducted at waiting area of Magnetic Resonance Imaging outpatient unit at El Menofyia University Hospital.

\section{Sample}

A convenient sample of 50 female adolescent who attending in MRI unit appointment file at El Menofyia University Hospital 2 days/ week for a period of 10 months (from February,2012 till December , 2012) and according to the following criteria:

Female adolescent age ranged from 12 to 18 years and had no previous history of MRI examination; no concomitant invasive procedure performed on the patients.

\section{Tools of Data Collection:}

Four tools were used to collect data for the study:

It was developed by the researcher after review of the related literature. it was contain four tools
Tool I part I:-Socio-demographic Data :

This tool was designed by the researchers which includes data about the general characteristics of the study sample such as: age, and level of education, etc.

\section{Part II-Patient Assessment Knowledge} sheet: related to machine, preparation for the procedure, and contraindications for MRI.

\section{Tool II-Claustrophobia Assessment}

\section{Sheet includes:}

1-Horizontal visual analogue scale of 10 cm (0-100). ${ }^{(25)}$ The patient marks on the line the point that they feel represents their perception of their current state of sensation or feeling or response to be measured. Subjects respond to the (HVAS) by placing the mark through the mark through the line at position which best represent their current perception of a given phenomenon between the labeled extremes. Its most common form is 100 mm horizontal line.

2- Patient subjective symptoms of claustrophobia during the procedure.

\section{Tool III-State-Trait Anxiety Inventory} (STAI). (26)

STAI, is a self-reporting test, was used to assess state anxiety levels. It has demonstrated reliability and validity in previous studies. A valid and reliable English version of the scale was used. 
Total possible anxiety scores range from 20 to 80 (higher scores indicate higher anxiety levels).

Validity of the tools were determined by five experts Menoufyia University who reviewed these instruments and judged it to measure what was intended to be measured (face validity). Experts were also asked to judge the items for their adequacy. Modifications of the tool were made according to the panel's judgment on clarity of sentences, appropriateness of content, sequence of items, and accuracy of scoring and recording of items (content validity). Reliability analysis was used to determine the extent to which the items in the questionnaire are related to each other. It was assessed by applying the tools twice on 5 female adolescents' who were excluded from the study. (Test -retest).

Fifty female adolescent interviewed individually to assess their knowledge, anxiety level and claustrophobia intensity (pretest). After that each adolescent received instructions designed by the researcher before MRI examination in addition to the routine hospital instructions. Patients examined; in this unit are on a waiting list and are given an appointment for the examination.

\section{A booklet developed by the researchers.}

The booklet was designed by the researchers after reviewing related literature to provide patients with information about the nature and sequence of the examination and about the MR imaging machine (its structure, uses and preparation). In addition, the instructions included a description and discussion of relaxation techniques, e.g. blinding, imaginative visualization and breathing techniques that might be useful to the patient in managing anxiety and claustrophobia during the examination. The booklet written in Arabic for easy understand.

\section{Scoring system:}

Questionnaire was designed to gather information about the procedure. The questions were comprised of 16 questions. Score +1 for satisfactory $(50 \%$ and more score) answer, zero for unsatisfactory (less than 50\% score) answer was considered

\section{Method :}

An official permission to conduct the study was obtained from the responsible authorities the director and the head of rays department of El Menofyia University Hospital. Before conducting the study, personal communication was done after explaining the aim of the study.

Ethical consideration: Oral consent was obtained from female adolescent after explanation of the aim of the study to participate in the study. Confidentiality and privacy of their information obtained from them .They had the full right to withdraw from the study. 
The tools I,II,III of the study was developed and was tested for its content validity after thorough review of related literature by 5 experts in the pediatric nursing field.

Pilot study: A pilot study was done on a group of 5 female adolescent patients undergoing MRI from Magnetic Resonance Imaging outpatient unit at El Menofyia University Hospital. It was conducted to check the clarity of the statements, and simplicity of questions and to check the most common topics related to the study. These numbers of pilot study were excluded from the total number of study sample. Necessary corrections and modifications were done based on findings of pilot study to develop the final form of the tools.

Field Work: The field work was carried out within duration of 10 months(from (February,2011 till December, 2012), data collected ( assessment phase) for 2 days per week from 9 a.m to 2 p.m, the implementation phase was done in the same days through interview with each adolescent individually using study tools. The health instructions was carried out in one session after assessment phase for each adolescent including time for discussion. All these was done through pre and post administration of an interviewing questionnaire.

\section{Program Construction:}

\section{Program Assessment Phase:}

The program was designed by the researchers based on results obtained from nursing assessment tools. It was revised and modified according to the related literature.

\section{Program Development and}

\section{Implementation Phase:}

Once the official permission was granted. The researcher taking list of patients' names and medical record numbers with the schedule for patients was obtained from appointment book and individualized health instruction begins with assessment of adolescents and mutual setting of the specific objectives. Each female adolescent patient individually completed the questionnaire before they began the intervention as well as before beginning the procedure of MRI examination. The researcher provided the study group with knowledge about setting and apparatus to relieve their anxiety and claustrophobia. Female adolescent patients who could not read or write were helped by the researchers to fill out the sheet. Duration of health education session ranged from $30-45$ minutes for each patient.

The implementation of Program was based on modified lectures, shared discussion, using visual aids as pictures, posters and 
designed booklet that was given for each adolescent who participate in the study.

\section{General Objectives of the Health}

\section{Education Program:}

The general objective of the program was to investigate the health instructions for female adolescent outpatients undergoing Magnetic Resonance Imaging on anxiety levels and claustrophobia.

\section{Contents of Health instructions}

\section{Program:}

Adolescents' knowledge regarding MRI, types of apparatus, uses, risks, contraindications, questions and answers about MRI.

Preparation for patient (before, during and after procedure).

Instructions for psychological support to reduce anxiety and claustrophobia.

\section{Program Evaluation Phase:}

Evaluation was applied after program implementation by using the same pretest after the end of the sessions in order to identify differences, similarities and areas of improvement and defects.

\section{Statistical analysis:}

Data were coded for entry and analysis using SPSS statistical software package version 17. Data were presented using descriptive statistics in the form of frequencies and percentages and tested by Wilcoxon tests. Quantitative variables were presented in the form of means and standard deviations, and tested by t-test. The level of significance taken as $\mathrm{P}<0.05$

\section{Results:}

Table (1) shows Percent Distribution of Female Adolescent Related to Sociodemographic Characteristic, in relation to age the mean age of the female patients in the sample was $(15.1200+2.10577)$ years, regarding to education relatively half of them (48\%) finished secondary education. Table (2) shows percent distribution of female adolescents related to knowledge about machine before magnetic resonance imaging; there was statistical significance difference of patient's knowledge after instructions. The minority of adolescent female patients (14\%) had satisfactory knowledge in pretest as compared by less than three quarters $(70 \%)$ of them in post test. While regarding uses of machine; the majority of them $(94 \%)$ had unsatisfactory knowledge in pretest as compared by $32 \%$ of them in post test with highly statistically significant difference.

Figure $(\mathbf{1 , 2}, \mathbf{3})$ :clarifies that $88 \%$ of adolescent patients had unsatisfactory knowledge in pretest regarding remove jewelries as a preparation before MRI exam as compared to only $4 \%$ in post test. Also, 34\% of them had satisfactory pretest knowledge regarding preparation during 
MRI exam compared to all of them $(100 \%)$ in past test with highly statistically significant difference.

Table (4) reveals Relation between Pre Test and Post Test related to total Knowledge scores of Female Adolescents; the differences between pre test mean score 23.1600 compared to 22.3800 in post test regarding total knowledge scores for female adolescent patient with statistically significant difference.

Table (5) shows comparison between Mean \& SD of total horizontal visual analogue scale of the patients in the Sample pre -post education. The mean score total fear visual analogue scale was $(14.0000 \pm 1.55183)$, with $\quad(\mathrm{T}=22.346$, $\mathrm{P}=.000 *$ ) before education compared to $(20.3400 \pm 1.34938)$ after education with highly statistically significant difference.

Table (6) illustrates Percent distribution of female adolescent related to Subjective Symptoms of Claustrophobia during MRI examination Majority of the patients in the sample $(84 \%, 76 \%, 66 \%)$ they had negative thoughts (afraid from MRI machine; fear of diagnostic findings; I feel fainting) respectively in pre health education, changed into positive thoughts $(88 \%, 84 \%, 88 \%)$ respectively with highly statistically difference.
Table (7) shows Percent distribution of female adolescent related to anxiety levels after MRI examination. There is highly statistically significant difference among levels of anxiety from pre test and post test.

Table (8): illustrates Relation Between Pretest and post test of Female adolescent related to Total Anxiety Scores Before and after MRI Examination. There is highly statistically significant difference between pretest and post test in relation to total anxiety scores.

Table (9): reveals Strategies to Cope With Anxiety and Claustrophobia Before and During MRI in Percentage Distribution; There is a difference between pretest knowledge in Reading Quran 40\% compared to $60 \%$ in post test. Furthermore, there is a difference between pretest knowledge for no need to complete MRI $24 \%$ compared to $6 \%$ in posttest. 
Table (1) Percent Distribution of Female Adolescent Related to Socio-demographic Characteristic

\begin{tabular}{|l|c|c|}
\hline Socio-demographic Characteristic & $\begin{array}{c}\text { (n=50) } \\
\text { No }\end{array}$ & \% \\
\hline Age & & 24 \\
\hline $12-<14$ years & 12 & 32 \\
\hline $14<16$ years & 16 & 44 \\
\hline $16 \leq 18$ years & 22 & 8.0 \\
\hline Mean $\mathbf{S . D}$ & \multicolumn{2}{|c|}{$\mathbf{1 5 . 1 2 0 0 + 2 . 1 0 5 7 7}$} \\
\hline Educational Level & 4 & 44 \\
\hline Read and write & 22 & 48.0 \\
\hline Preparatory education & 24 & \\
\hline Secondary education & \multicolumn{2}{|c|}{} \\
\hline
\end{tabular}

Table (2): Percent distribution of Female Adolescents related to knowledge about machine :Before Magnetic Resonance Imaging

\begin{tabular}{|l|c|c|c|c|c|c|}
\hline \multicolumn{1}{|c|}{$\begin{array}{c}\text { Knowledge about } \\
\text { machine }\end{array}$} & \multicolumn{2}{|l|}{$\begin{array}{l}\text { Pre test knowledge } \\
\text { (n=50) }\end{array}$} & \multicolumn{2}{l|}{$\begin{array}{l}\text { Post test } \\
\text { knowledge } \\
\text { (n=50) }\end{array}$} & Z & P \\
\cline { 2 - 6 } & No & \% & No & \% & & \\
\hline $\begin{array}{l}\text { Description machine } \\
\text { Satisfactory }\end{array}$ & 7 & 14 & 35 & 70 & & \\
Unsatisfactory & 34 & 86 & 15 & 30 & -4.072 & $.000^{*}$ \\
\hline Machine work & 5 & 10 & 35 & 70 & & \\
Satisfactory & 45 & 90 & 15 & 30 & -4.774 & $.000^{*}$ \\
Unsatisfactory & 3 & 6 & 34 & 68 & -4.576 & \\
\hline Uses & 47 & 94 & 16 & 32 & & $.000^{*}$ \\
Satisfactory & 8 & 16 & 38 & 76 & & \\
Unsatisfactory & 42 & 84 & 12 & 24 & -5.145 & $.000^{*}$ \\
\hline Duration & & & & & & \\
Satisfactory & & & & & & \\
Unsatisfactory & &
\end{tabular}



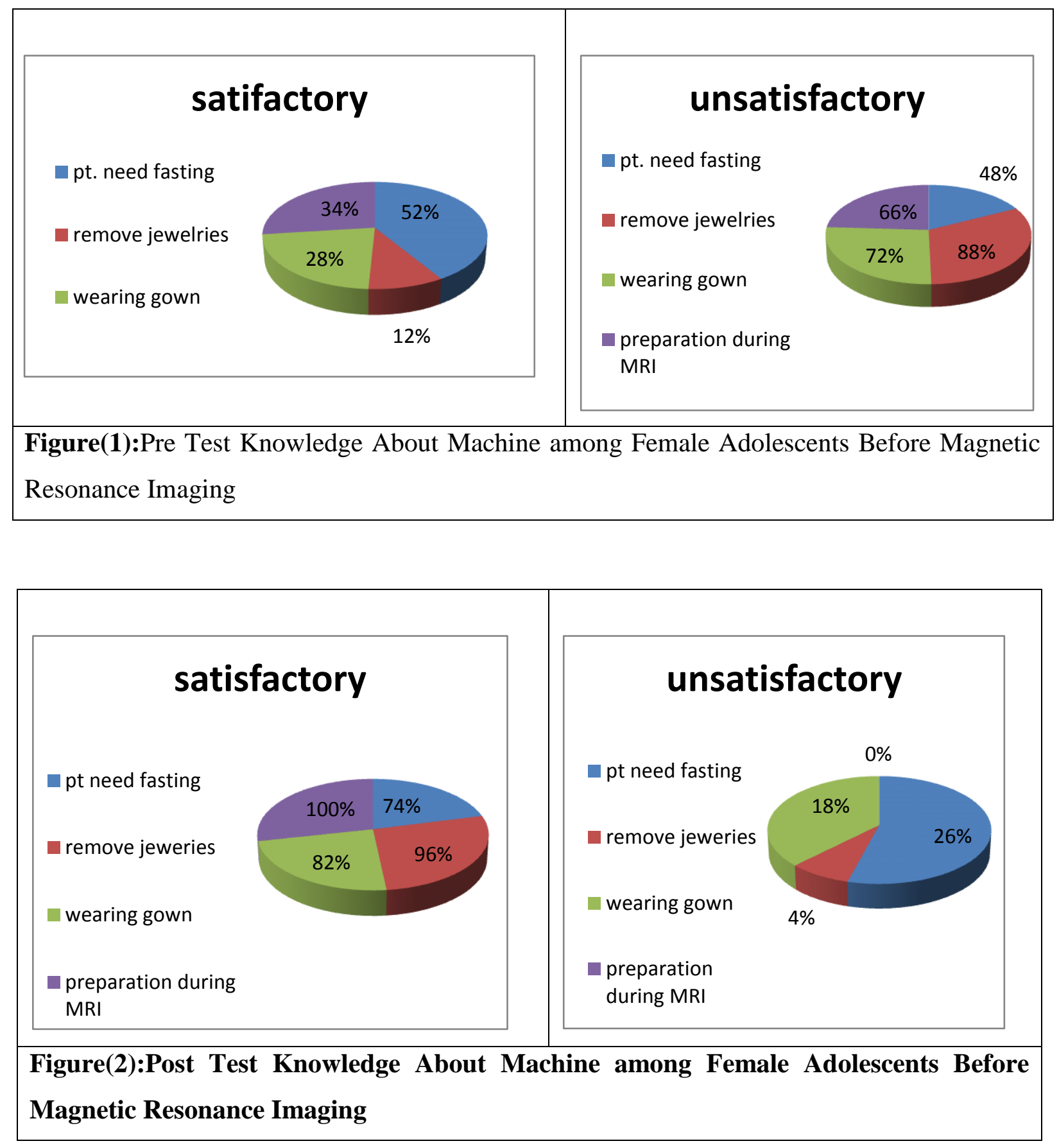


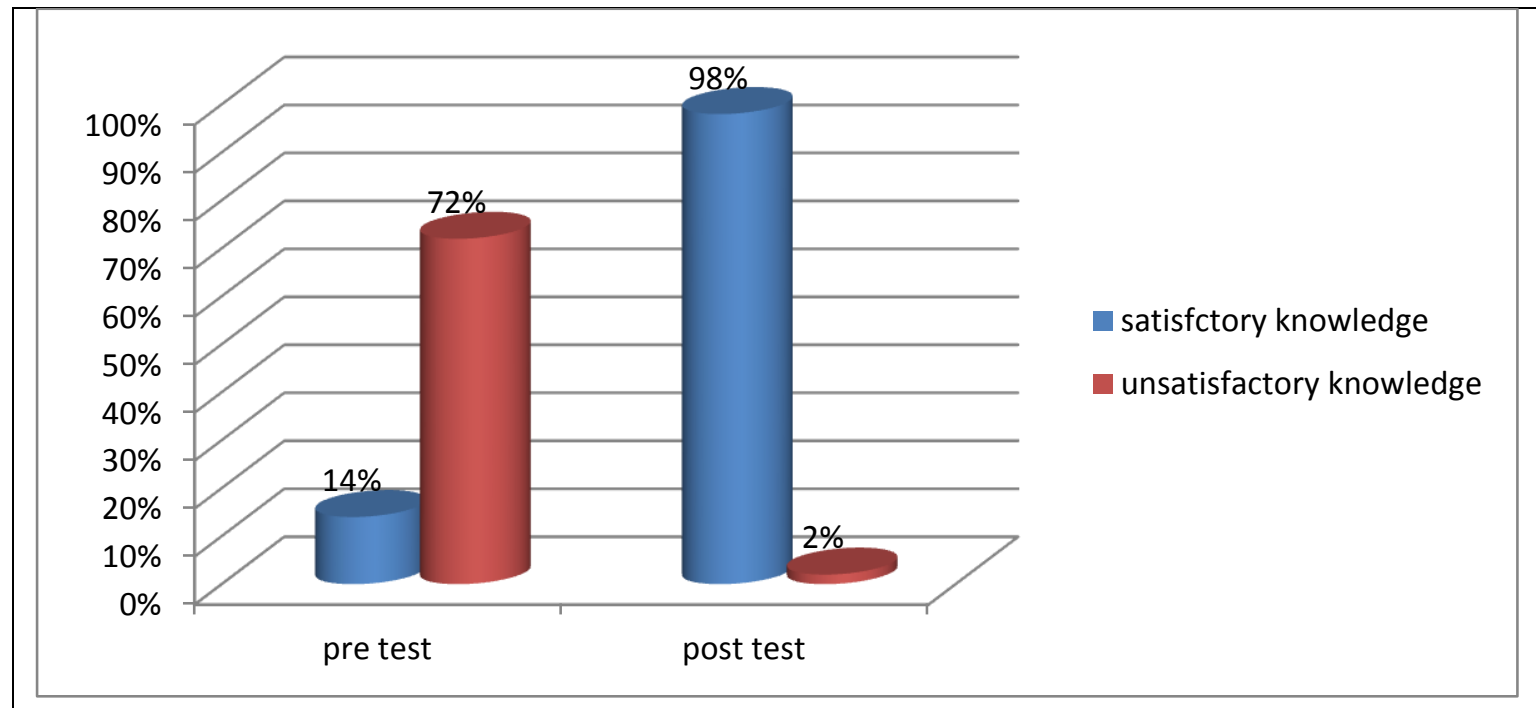

Figure (3):Differences of pre test and post test knowledge about contraindications for MRI

Table (4): Relation between Pre Test and Post Test related to total Knowledge scores of Female Adolescents

\begin{tabular}{|c|c|c|c|c|}
\hline Variable & $\mathbf{M}$ & SD & $\mathbf{t}$ & $\mathbf{P}$ \\
\hline Pre Test Total Knowledge Score & 23.1600 & $\mathbf{1 . 7 9 9 7 7}$ & \multirow[t]{2}{*}{2.086} & \multirow[t]{2}{*}{$.042 *$} \\
\hline POST Test Total Knowledge Score & 22.3800 & 1.86142 & & \\
\hline
\end{tabular}

Table (5): Differences between Pretest and Post Test in Relation to Total Horizontal Visual Analogue scale Scores of Claustrophobia Before And After MRI Examination

\begin{tabular}{|ll|c|c|c|c|}
\hline & M & SD & t & P \\
\hline PRE & Test & 14.0000 & 1.55183 & & \\
\cline { 1 - 3 } POST & Test & 20.3400 & 1.34938 & \multirow{2}{*}{22.346} & .000* \\
\hline
\end{tabular}

Table(6): Percent distribution of Female Adolescent Related to Subjective Symptoms of Claustrophobia during MRI Examination

\begin{tabular}{|c|c|c|c|c|c|c|c|c|c|c|}
\hline \multirow{3}{*}{ Variable } & \multicolumn{4}{|c|}{$\begin{array}{l}\text { Pre Test knowledge } \\
(n=50)\end{array}$} & \multicolumn{4}{|c|}{$\begin{array}{l}\text { Post Test knowledge } \\
(n=50)\end{array}$} & \multirow{3}{*}{$\mathbf{Z}$} & \multirow{3}{*}{$\mathbf{P}$} \\
\hline & \multicolumn{2}{|c|}{ yes } & \multicolumn{2}{|c|}{ no } & \multicolumn{2}{|c|}{ yes } & \multicolumn{2}{|c|}{ no } & & \\
\hline & No. & $\%$ & No. & $\%$ & No. & $\%$ & No. & $\%$ & & \\
\hline $\begin{array}{l}\text { I am afraid from MRI } \\
\text { machine }\end{array}$ & 42 & 84 & 8 & 16 & 6 & 12 & 44 & 88 & 5.692 & $.000 *$ \\
\hline $\begin{array}{l}\text { Fear of coming to harm at } \\
\text { machine }\end{array}$ & 34 & 68 & 16 & 32 & 9 & 18 & 41 & 82 & 4.642 & $.000 *$ \\
\hline Fear of diagnostic findings & 38 & 76 & 12 & 24 & 8 & 16 & 42 & 84 & 5.145 & $.000 *$ \\
\hline I will lost my mentality & 38 & 76 & 12 & 24 & 10 & 20 & 40 & 80 & 4.950 & $.000 *$ \\
\hline
\end{tabular}


Tanta Scientific Nursing Journal

\begin{tabular}{|l|c|c|c|c|c|c|c|c|c|c|}
\hline I feel isolate & 36 & 72 & 14 & 28 & 7 & 14 & 43 & 86 & 5.385 & $.000^{*}$ \\
\hline Fear of closed spaces & 37 & 74 & 13 & 26 & 5 & 10 & 45 & 90 & 5.357 & $.000^{*}$ \\
\hline I feel suffocate & 38 & 76 & 12 & 24 & 13 & 26 & 37 & 74 & 5.568 & $.000^{*}$ \\
\hline $\begin{array}{l}\text { I afraid from restriction of } \\
\text { movements }\end{array}$ & 33 & 66 & 17 & 34 & 5 & 10 & 45 & 90 & 3.615 & $.000^{*}$ \\
\hline $\begin{array}{l}\text { I Want someone with me } \\
\text { at examination room }\end{array}$ & 33 & 66 & 17 & 34 & 7 & 14 & 43 & 86 & 4.950 & $.000^{*}$ \\
\hline I feel fainting & 33 & 66 & 17 & 34 & 6 & 12 & 44 & $\mathbf{8 8}$ & $\mathbf{4 . 8 4 9}$ & $.000^{*}$ \\
\hline I am going to pass out & 6 & 12 & 44 & 88 & 44 & 88 & 6 & 12 & $\mathbf{5 . 2 4 0}$ & $.000^{*}$ \\
\hline
\end{tabular}

Table (7): Percent Distribution of Female Adolescent Related to Anxiety Levels After MRI Examination

\begin{tabular}{|c|c|c|c|c|c|c|}
\hline \multirow[b]{2}{*}{ Anxiety Level } & \multicolumn{2}{|c|}{$\begin{array}{l}\text { Pre test knowledge } \\
(n=50)\end{array}$} & \multicolumn{2}{|c|}{$\begin{array}{l}\text { Post test knowledge } \\
(\mathbf{n}=50)\end{array}$} & \multirow[b]{2}{*}{$\mathbf{Z}$} & \multirow[b]{2}{*}{$\mathbf{P}$} \\
\hline & No & $\%$ & No & $\%$ & & \\
\hline$(1-19)$ & $\mathbf{0}$ & $\mathbf{0}$ & $\mathbf{0}$ & $\mathbf{0}$ & & \\
\hline$(20-39)$ & $\mathbf{0}$ & $\mathbf{0}$ & 36 & 72 & $\begin{array}{c}- \\
6.157-\end{array}$ & $.000 *$ \\
\hline Moderate $(40-59)$ & 20 & 40 & 14 & 28 & & \\
\hline$(60-80)$ & 30 & 60 & $\mathbf{0}$ & $\mathbf{0}$ & & \\
\hline
\end{tabular}

Table (8): Relation Between Pretest and post test of Female adolescent related to Total Anxiety Scores Before and after MRI Examination

\begin{tabular}{|l|c|c|c|c|}
\hline & M & SD & T & P \\
\hline Pretest Total Anxiety & $\mathbf{6 0 . 5 8 0 0}$ & 4.2237 & & \\
Posttest Total Anxiety & 48.88800 & 4.71922 & 15.269 & $0.000 *$ \\
\hline
\end{tabular}

Table (9): Strategies to Cope With Anxiety and Claustrophobia Before and During MRI in Percentage Distribution

\begin{tabular}{|l|c|c|c|c|}
\hline \multirow{2}{*}{\multicolumn{1}{|c|}{ strategies }} & \multicolumn{2}{c|}{$\begin{array}{c}\text { Pre test knowledge } \\
(\mathbf{n = 5 0})\end{array}$} & \multicolumn{2}{c|}{$\begin{array}{c}\text { Post test knowledge } \\
(\mathbf{n = 5 0})\end{array}$} \\
\cline { 2 - 5 } & $\mathbf{N o}$ & $\%$ & No & $\%$ \\
\hline $\begin{array}{l}\text { Accompanying someone with me at } \\
\text { examination room }\end{array}$ & $\mathbf{9}$ & $\mathbf{1 8}$ & $\mathbf{5}$ & $\mathbf{1 0}$ \\
\hline Reading Quran & $\mathbf{2 0}$ & $\mathbf{4 0}$ & $\mathbf{3 0}$ & $\mathbf{6 0}$ \\
\hline Close my eyes & $\mathbf{9}$ & $\mathbf{1 8}$ & $\mathbf{1 2}$ & $\mathbf{2 4}$ \\
\hline No need to complete MRI & $\mathbf{1 2}$ & $\mathbf{2 4}$ & $\mathbf{3}$ & $\mathbf{6}$ \\
\hline
\end{tabular}




\section{Discussion:}

Yesterday's girl is today's adolescent and tomorrow's mother. Approximately 9\% (one fifth) of the world's population is in the age group of 10-19 years, as they are passing through a transitional period from childhood to adulthood, they are undergoing a lot of physical as well as psychological stress due to the changes taking place in the body. ${ }^{(27)}$

The development of MRI has been extraordinary during the last few decades and the areas of examination are growing which means that examinations. This emphasizes the importance of studying ways to improve patient care and how image quality may be improved by patient preparation. ${ }^{(7),(9),(28)}$

The study findings revealed that about half of study sample (48\%) finished secondary education, and more than one third of them (44\%) their age ranged between $16 \leq 18$ years. the majority of sample were having unsatisfactory knowledge related to machine, procedure preparation, contraindication, and time needed for the procedure. This may be due to low level of education (8\% read and write, $44 \%$ preparatory education ).

Over the first 15 year period (1989-2003) of performing MRI for clinical indications observed a failure rate of approximately
$3 \%$ because of patient claustrophobia. Currently, the failure rate is approximately $1.0-1.5 \%$, with the improvement probably arising from improved magnetic design producing smaller scanners that appear less daunting for the patients. ${ }^{(18)}$

Meanwhile, a highly significant difference was found between the sample when the total horizontal visual analogue scale Scores of claustrophobia were compared after the procedure of MRI examination and after instructions were given. This may be explained by the effect of teaching patients who has anxiety and claustrophobia lowering. These study findings agree with ${ }^{(30)}$ who concluded that, State anxiety of all subjects reached the highest score and level at the time just before cardiac catheterization and before education intervention and the lowest score and level recorded at the time following the procedure. Furthermore, a lower level of anxiety was experienced by the experimental subjects who received the education intervention.

In agreement with the study findings, (31) reported that $13 \%$ of patients undergoing MRI experience panic attacks during the procedure ,the MRI procedure alone could lead not only to the triggering of preexisting claustrophobia but also to the onset of claustrophobia itself: there is 
some very limited evidence to suggest that, in some patients, claustrophobia may be initially provoked by the experience of being in the scanner. Also, ${ }^{(8)}$ found that Between $1 \%$ and $15 \%$ of all patients scheduled for MR imaging suffer from claustrophobia and cannot be imaged, or they require sedation to complete the scan. In relation to completion of magnetic resonance imaging, it is obvious that, all of study group subjects completed the procedure successfully. This may be explained by the effect of knowledge which introduced for the patients that has on anxiety and claustrophobia lowering. also, this is the first experience for all patients to be in the MRI machine which itself can be a main source of claustrophobia and anxiety

The discrepancy between the number of people reporting anxiety and the number of prematurely terminated scans suggests that many "completers" still experience substantial anxiety. MRI-related anxiety is likely caused by the novelty of the experience, the confined and noisy space within the scanner, fear of suffocation or that the scanner will be harmful, and concern about anticipated findings. ${ }^{(32)}$

Concerning the severity of anxiety level, this study revealed that a highly significant difference was found immediately after the procedure. Majority of the patients in the sample $(60 \%, 40 \%)$ experienced moderate to severe state anxiety levels preintervention. In contrast, $(72 \%)$ of the patient experienced a severe level of anxiety post-intervention.

These findings agree with, (25) who indicated that the study group experienced mild to moderate anxiety levels, while, around two-thirds of the control group exhibited moderate to severe anxiety after examination. Amount of anxiety experienced by the patients during the scan may be related to various factors as reported by ${ }^{(34)}$ who stated in their study that "amount of anxiety experienced during the scan was related to the perceived amount of time spent having physical symptoms of panic( 45- $60 \mathrm{~min}$.). Study findings showed that, the majority of both groups were reading Quran as a strategy to cope with anxiety and claustrophobia before and during MR imaging. This may be explained that they are Muslims and all of us think that the cure is in Quran as our God said.

These results were in agreement with ${ }^{(25)}$ who reported in her study that as within Egyptian culture many people believe that they can become sick if God decides to test their faith. This is also illustrated from what was said during data collection, when 
most patients gave thanks to God and continued thanking God because acceptance of illness may be rewarded by its relief. Thus, a person's faith, religion and spiritual beliefs can help calm emotions and reactions to stressors, and can be a vital support in times of medical crises.

Other study reported that One-session treatment of cognitive therapy for specific phobias has been found to be highly effective, and those patients with preexisting claustrophobia may benefit from one-session treatment, This intervention was based on the factors found to be most associated with anxiety in the scanner and the strategies commonly used to combat it, and the most strategies they used were a very simple breathing exercise they taught. ${ }^{(33)}$

\section{Conclusion:}

Female adolescent who undergoing magnetic resonance imaging examination cannot terminate the procedure due to producing anxiety and claustrophobia, so health instructions for those is very necessary, which has an effect on lowering anxiety and claustrophobia related to magnetic resonance imaging examination.

\section{Recommendations:}

The researchers suggested conduction of a designed program for patients who cannot terminate the procedure successfully and reappointed for another examination.

Patient meeting with psychologist before MRI.

Establishing enjoyable posters and pamphlets into the MRI waiting room.

Teach the female adolescents' methods of coping therapeutically with claustrophobia and anxiety.

Presences of relative with female adolescents during preparation for MRI.

Create methods of communications with staff nursing during MRI.

Further studies must be conducted in this field on larger sample size for both genders to identify the other factors related to producing anxiety and claustrophobia.

\section{References:}

- Robinson M, Peake L, Ditchfield M. Magnetic Resonance Imaging Findings in a Population-Based Cohort of Children with Cerebral Palsy. Dev Med Child Neurol 2009; 5 :(1) 39-45.

- Hermann B, Dabbs K, Becker T. Brain Development In Children With New Onset Epilepsy: A Prospective Controlled Cohort Investigation. Epilepsies, 2010. Available at :doi:10.1111/j.15281167.2010.02563

- Enders J, Zimmermann E, Rief M, Martus P, Klingebiel, Asbach R, 
Klessen C, Diederichs G, Bengner T, Teichgräber, Hamm UB and Dewey M. Reduction Of Claustrophobia During Magnetic Resonance Imaging: Methods And Design Of The "CLAUSTRO" Randomized

Controlled Trial. BMC Medical Imaging 2011;

11:4 doi:10.1186/1471-2342.

- MacIsaac HK, Thordarson DS, Shafran R, Rachman S, Poole G. Claustrophobia And The Magnetic Resonance Imaging Procedure. Journal of Behavioural Medicine,1998; 21(1):255-268.

- Törnqvist E. Going Through Magnetic Resonance Imaging Patients' Experiences And The Value Of Information And Preparation For Adults And Children. Lund University, Sweden, Department of Health Sciences, Lund University, Lund, Sweden 2010.

- Radiological Society of North America. Safety-MR. Retrieved July 9; from http://www.radiologyinfo .org/en/info.cfm?pg=bodymr 2012

- Westbrook C, Kaut Roth C, \& Talbot J. MRI in Practice, ${ }^{3 \text { ed.. }}$ Oxford: John Wiley and Sons2005, $34-5$.

- Dewey M, Schink T, Dewey C. Claustrophobia During Magnetic
Resonance Imaging: Cohort Study in Over 55,000 Patients. J Magnet Reson Imag 2007; 26 (1):1322-27.

- McRobbie D, Moore E, Graves M , \& Prince, M. Magnetic Resonance Imaging from Picture to Proton 2 ed. Cambridge: Cambridge University Press Co., 2007.

- Dill T. Contraindications To Magnetic Resonance Imaging Heart 2008; 94:943-948.

doi:10.1136/hrt.2007.125039

- Poulton R, Milne BJ, Craske MG, \& Menzies RG. A Longitudinal Study Of The Etiology of Separation Anxiety. Behaviour Research and Therapy 2001; 39(12): 1395-1410.

- Weiss D, \& Last C. Developmental Variations In The Prevalence And Manifestations Of Anxiety Disorders. The Developmental Psychopathology Of Anxiety Oxford: Oxford University Co., 2001; 27-42.

- Costello E, Egger H \& Angold A. Developmental Epidemiology of Anxiety Disorders. In T. H. Ollendick \& J. S. March , Phobic Anxiety Disorders In Children And Adolescents: A Clinician's Guide To Effective Psychosocial And Pharmacological Interventions 
Oxford, UK: Oxford University Press.2003;61-91.

- Costello E, Mustillo S, Erkanli A, Keeler G \& Angold A. Prevalence And Development Of Psychiatric Disorders In Childhood And Adolescence. Arch Gen Psychiatry 2003; 60(1): 837-844.

- Tischler V, Calton T, Williams M, Cheetham A. Patient Anxiety In Magnetic Resonance Imaging Centres: Is Further Intervention Needed? Radiography 2008; 14(3):265-266.

- Zeidner M, \& Matthews G. Anxiety 101. New York: Springer Publishing Co., 2011;1-40.

- Bigley J, Griffiths P, Prydderch A, Romanowski C, Miles L, Lidiard H, and Hoggard $\mathrm{N}$ Neurolinguistic Programming Used To Reduce The Need For Anaesthesia In Claustrophobic Patients Undergoing MRI. Br J Radiol. February 2010; 83(986): 113-117. doi: $10.1259 / \mathrm{bjr} / 14421796$

- Ottosson, J-O. (2009). Psykiatri. (7:e uppl.) Stockholm: Liber. 400 s. (Alt 8:e utgåvan.)

- Eshed I, Althoff C, Hamm B, \& Hermann. Claustrophobia And Premature Termination Of Magnetic Resonance Imaging Examinations. J
Magn Reson Imaging 2007; 26(2): 401-404.

- Harned RK, 2nd, \& Strain J. MRICompatible Audio/Visual System: Impact On Pediatric Sedation. Pediatr Radiol 2001; 31(4): 247-250.

- Hallowell L, Stewart S, Amorim E $\&$ Ditchfield $M$.Reviewing The Process Of Preparing Children For MRI. Pediatr Radiol2008; 38(3): 271279.

- Tornqvist E, Mansson A, Larsson EM, Hallstrom I. It's Like Being In Another World — Patients' Lived Experiences Of Magnetic Resonance Imaging. J Clin Nurs2006; 15 (1) : 954-961.

- Meriau K, Wartenburger I, Kazzer P, Prehn K, Villringer A, van der Meer E, Heekeren HR. Insular Activity During Passive Viewing Of Aversive Stimulire"Ects Individual Differences In State Negative Effect. Brain And Cognition2009; 69:73-80.

- Selim M. Effect Of Pre-Instruction On Anxiety Levels Of Patients Undergoing Magnetic Resonance Imaging Examination. East Mediterr Health J2001; 7(3): 519- 525.

- Gould, D., 2001 Blackwell Science Ltd, Journal of Clinical Nursing, 10, 697-706 
- Spielberger C, Gorsuch R, Lushene R. State-Trait Anxiety Inventory. Palo Alto, Consulting Psychologist Press 1983.

- Eswi A, Helal H, and Elarousy W. Menstrual Attitude and Knowledge among Egyptian Female Adolescents Journal of American Science2012;8(6): 555-565

- Chandromohan D, Parikh S, Akhtar N, \& Delgado P .Review and update of MRI for Clinicians. Mo Med2005; 102(2):120-123.

- Chan D, Cheung H. The Effects Of Education On Anxiety Among Chinese Patients With Heart Disease Undergoing Cardiac Catheterization in Hong Kong 2003.

- Harris S and Menzies R. Predicting anxiety in Magnetic Resonance Imaging Scans. Int $\mathrm{J}$ Behav Med 2004; $11: 17$.

- McGlynn F, Smitherman T, Hammel J, Lazarte A: Component Fears Of Claustrophobia Associated With Mock Magnetic Resonance Imaging. Journal Of Anxiety Disorders; 2007;21(1): 367-380.

- Thorpe S, Salkovskis, PM, Dittner A.Claustrophobia in MRI: The Role Of Cognitions. Magnetic Resonance Imaging 2008; 26: 1081-1088.
- Street RL, Gorgon H, and Haidet P. Physicians' Communication And Perceptions Of Patients: Is It How They Look, How They Talk, Or Is It Just The Doctor? Soc Sci Med2007; 65: 586-59. 